\title{
PARTICIPAÇÃO SOCIAL NO MERCOSUL: UMA PROPOSTA DE MENSURAÇÃO
}

\author{
Acácio Vasconcelos Telechi ${ }^{1}$
}

\begin{abstract}
Resumo
Ao longo do desenvolvimento do Mercosul, a participação social foi colocada como um elemento legitimador da integração. Contudo, diversos são os obstáculos identificados pela literatura para a concretização dessa participação. Dentre elas, destaca-se os limites impostos pela baixa institucionalização e intergoverrnamentalidade. Assim, propõe-se um indicador para mensurar a participação de atores fora da burocracia estatal no Mercosul desde 1991 até 2019 . O Indicador de Participação Social (IPS) foi composto por três dimensões: (i) institucionalização, (ii) potencial inclusivo e democratizante e (iii) representataividade. Por meio do IPS, foi possível identificar três fases da participação social e o possível início de uma quarta. A primeira foi chamada de "fase do ensaio", de 1991 a 1993, com o início da participação, de maneira pontual e setorizada. A segunda, denominada "fase do prólogo", entre 1994 e 2004, com muito baixa participação, porém com crescimento rápido por conta da institucionalização do Protocolo de Ouro Preto seguido de estabilização. A terceira, a "fase do desenvolvimento", de 2005 a 2015, que chega a ter participação média puxada pelas iniciativas nacionais dos Estados-membros. A partir de 2016, pode-se identificar uma possível reversão de tendência, com o que se chamou de "fase da incógnita", dada a incerteza quanto ao futuro da integração no que tange à dimensão social. Identifica-se um crescimento da participação social e da representatividade apesar de todos os limites impostos pela baixa institucionalização. Por outro lado, persiste a centralidade dos Estados no sentido de possibilitar a entrada dos atores nãoestatais.
\end{abstract}

Palavras-Chave: participação social; atores não-estatais; Mercosul; indicador.

\section{INTRODUÇÃO}

As recentes dissonâncias entre Brasil e Argentina, os dois principais sócios do Mercosul, colocam desafios profundos à integração. Todavia, não é a primeira vez que o bloco é questionado. Contendas econômico-comerciais entre os dois países no final da década de 1990 levantaram dúvidas a respeito da eficácia do Mercosul. A partir do "relançamento" do bloco, outras dimensões da integração ganharam atenção com objetivo de aumentar a sua legitimidade, entre elas, a social.

Fortaleceu-se uma "retórica democrática e participativa" (TAJRA, 2019). Em diversas decisões do Conselho Mercado Comum (CMC), foi ressaltada a importância da participação de atores não-estatais². Em 2017, a Decisão n’ 30 trouxe nos considerandos "que a participação social no

\footnotetext{
${ }^{1}$ Mestrando em Ciência Política na Universidade Federal do Paraná (UFPR); acaciotelechi@gmail.com; ORCID: https://orcid.org/0000-0003-1547-0497

2 ver, por exemplo, a parte do Programa de trabalho Mercosul 2004-2006 (Decisão 26/2003) que trata do Mercosul Social, colocando a necessidade de se ampliar instâncias participativas
} 
Mercosul constitui dimensão importante do processo de integração". Em seguida, a parte dispositiva da decisão buscou fortalecer e regulamentar a Unidade de Apoio à Participação Social (UPS).

Ao longo do seu desenvolvimento e aprofundamento, a integração regional passou a abrir diversos espaços para a participação de atores sociais. Como exemplos podemos citar o Foro Consultivo Econômico e Social (FCES), um dos primeiros órgãos a permitir a presença de atores fora da burocracia estatal, ainda que no começo limitado a sindicatos e empresários, sem incluir outros setores da sociedade civil. Há participação em algumas reuniões especializadas, como é o caso da Reunião Especializada de Agricultura Familiar (REAF) e da Reunião Especializada de Cooperativas do Mercosul (RECM). O Subgrupo de Trabalho $\mathrm{n}^{\mathrm{o}} 10$ sobre Assuntos Laborais, Emprego e Seguridade Social tem o formato tripartite, onde representantes dos Estados, dos empresários e dos trabalhadores estão presentes.

Em 2006, realizou-se a I Cúpula Social do Mercosul (CSM), configurando-se como uma esfera importante de participação da sociedade civil, uma vez que contou com a presença de diversas organizações da sociedade civil (OSCs). Nos 10 anos seguintes, 21 cúpulas foram organizadas, envolvendo mais de 2.800 OSCs, de diferentes tamanhos, temas e países (MARTINS; ALBUQUERQUE; GOMENSORO, 2011).

Se, por um lado, existe a retórica participativa, por outro, há dificuldades permanentes na concretização da participação social. O que mais aparece como um obstáculo para a sociedade civil é a questão da institucionalização da participação (ALEMANY; LEANDRO, 2006; MARTINS; ALBUQUERQUE; GOMENSORO, 2011; MESQUITA; BELÉM LOPES, 2018; RIBEIRO, 2018; TAJRA, 2019; VAZQUEZ, 2008). O desenho institucional do bloco não a incentiva dado (i) a sua intergovernamentalidade, (ii) a característica consultiva dos órgãos em que a sociedade civil está presente, (iii) falta de regras bem definidas para a participação, entre outros.

Além disso, há questões ligadas com a própria organização da sociedade civil, tais como: (i) forte grau de elitização da representação dos atores sociais; (iv) maior representação de empresários do que de trabalhadores; (v) falta de recursos financeiros; (vi) alta rotatividade dos representantes; e (vii) problemas para lidar com alta tecnicidade de alguns temas. A literatura identifica, ainda, dificuldades oriundas da atuação das burocracias estatais: (viii) falta de uma visão de processo por parte dos tomadores de decisão e (ix) cultura de insulamento burocrático (ALEMANY; LEANDRO, 2006).

Dada essa lista de obstáculos à participação, Malamud (2011) levantou a hipótese de que uma maior abertura à sociedade civil não necessariamente levaria a uma maior participação. Com isso, este trabalho buscou entender como se comportou a presença da sociedade civil no Mercosul? Para 
responder à questão, propõe-se o Indicador de Participação Social (IPS) com a intenção de mensurar diacronicamente a participação desses atores dentro do Mercosul.

Este trabalho foi dividido em quatro partes além desta introdução. A primeira delas tratou sucintamente da história do Mercosul, bem como as transformações nos paradigmas da integração. Incluiu-se uma subseção para trazer o desenvolvimento da participação social. Foi realizado, também, um balanço não exaustivo da literatura sobre o tema, com o objetivo de identificar como foi estudada a participação no bloco e quais as dificuldades que a literatura aponta para tal.

A segunda parte dissertou a respeito da construção do Indicador de Participação Social (IPS), detalhando as suas dimensões e apresentado as variáveis que foram incluídas. Trata-se, portanto, do da sessão metodológica do trabalho. A terceira apresentou os resultados deste estudo e, na sessão seguinte, suas conclusões e discussões finais.

\section{DO “MERCOSUL FENÍCIO"AO "MERCOSUL SOCIAL"}

O Mercosul é fruto da aproximação entre Argentina e Brasil no contexto da redemocratização de ambos. Contou, para tanto, com intensa diplomacia presidencial, o que é entendido pela literatura como essencial para a constituição do bloco (DANESE, 1999; MALAMUD, 2011).

O Tratado de Assunção, que o funda em 1991, é assinado tendo como concepção ideal o "regionalismo aberto", isto é, focado em abertura comercial e constituição de um mercado comum. Essa característica, combinada com forte intergovernamentalismo e baixa intensidade, levou Caetano (2007) à classificação de "Mercosul fenício".

A perspectiva liberal dos líderes à frente da integração (como Collor e Menem), somada a uma superação da Guerra Fria, com a consequente "vitória" do liberalismo, e a aceitação do chamado “Consenso de Washington" ajudam a compreender o contexto no qual o Mercosul foi constituído e implementado (SERBIN; MARTINEZ; RAMANZINI JÚNIOR, 2012).

No final da década de 1990, a relação entre Argentina e Brasil passou por turbulências, as quais levantaram desconfianças com o processo de integração. Exemplos são os contenciosos comerciais, que, não podendo ser resolvidos no âmbito mercosulino, foram levados à Organização Mundial do Comércio; a desvalorização cambial brasileira em 1999, que afetou o balanço de pagamentos argentino, criticada pela falta de coordenação entre os dois países; e a crise econômicosocial argentina iniciada em 2001 em razão das consequências do Plano Cavallo, dificultando a condução da política externa do país. 
Além disso, o comércio intrarregional manteve-se pró-cíclico. A literatura identifica como causas: a falta de complementariedade econômica, as deficiências na infraestrutura e integração física, as medidas unilaterais, as instabilidades macroeconômicas e financeiras, a existência de barreiras não tarifárias, e a "reprimarização" das economias (SANAHUJA, 2012)

Nesse contexto, a incapacidade do Mercosul em servir como um foro de cooperação levaram ao questionamento da eficácia do bloco. O tom dessas dissonâncias pode ser identificado pelo pedido realizado pela União Industrial Argentina para uma "suspensão temporária do Mercosul" com o objetivo de proteger as empresas e as economias (CAETANO, 2011).

Em 2000, o então chanceler brasileiro, Luís Felipe Lampreia, após encontro com o seu homólogo argentino, Adalberto Rodríguez Giavarini, anunciou "a reversão do pessimismo sobre o Mercosul" e que haviam encontrado as bases para "relançar" o bloco (CLARÍN, 2000). Entretando, ainda pairavam as dúvidas oriundas dos desencontros entre os os países.

Com a ascensão de governos à esquerda, notadamente Néstor Kirchner e Lula, o processo de integração regional efetivamente é "relançado" (CAETANO, 2011). Muda-se do paradigma do "regionalismo aberto" para o "regionalismo pós-liberal" (SANAHUJA, 2012) ou "pós-hegemônico" (RIGGIROZZI; TUSSIE, 2012). Como consequência, percebe-se a construção e o aprofundamento da multidimensionalidade do bloco. Em outras palavras, questões para além do comércio passam a receber maior atenção.

Dentre essas dimensões, a social é a que mais interessa para os propósitos deste trabalho. Ou seja, a passagem de um "Mercosul fenício" para um "Mercosul social". Uma série de iniciativas podem ilustrar esse processo. Em 2006, é organizada a I Cúpula Social, considerada um marco para o que Martins e Silva (2011) chama de "segunda geração de mecanismos de participação no Mercosul". O projeto "Somos Mercosul" é um outro exemplo da tentativa de aproximar o processo de integração regional da sociedade civil. A seguir, encontra-se um breve balanço sobre a participação social.

\subsection{UMA BREVE HISTÓRIA DA PARTICIPAÇÃO SOCIAL}

Ainda que fosse previsto, no ato de fundação mercosulino, a integração multidimensional (incluindo a dimensão social), nos primeiros anos do bloco, a comercial foi a que mais se destacou. A busca pela concretização do "Mercosul fenício".

Contudo, isso não quer dizer a exclusão total de setores sociais na integração. O Protocolo de Ouro Preto, assinado em 1994, além de ser responsável por dar personalidade jurídica ao bloco e pela 
sua maior institucionalização, criou, também, o Foro Consultivo Econômico e Social (FCES). O órgão era aberto, inicialmente, para a participação de sindicatos e empresários. Com o seu desenvolvimento, passou a incluir outras organizações da sociedade civil (OSCs).

Além disso, o antigo Subgrupo de Trabalho n ${ }^{\circ} 11$, substituído pelo Subgrupo de Trabalho no 10 sobre Assuntos Laborais, Emprego e Seguridade Social (SGT-10), após demandas dos setores trabalhistas articulados, passou a incluí-los em suas reuniões, concretizando o formato tripartite. Nesse contexto, foi fundamental a atuação da Coordenadora das Centrais Sindicais do Cone Sul (CCSCS) (MARIANO, 2011). Tais atores criticaram o foco excessivamente comercialista do Mercosul, demandando maior participação social (BAPTISTA, 2020).

Além disso, se pensarmos em participação de atores para além da burocracia dos executivos nacionais, é necessário mencionar a Comissão Parlamentar Conjunta (CPC), sucedida pelo Parlamento do Mercosul (Parlasul). A então CPC foi prevista pelo Tratado de Assunção, porém sua estrutura institucional foi objeto do POP. O caráter consultivo, tanto da CPC quanto do Parlasul, limita bastante sua capacidade de formular a agenda do bloco (com apenas 5\% de suas propostas aprovadas pelo Conselho Mercado Comum (DRI; PAIVA, 2016)).

Uma vez que a literatura dá grande destaque para o caráter intergovernamental e à diplomacia presidencial, é compreensível a importância que as eleições de Néstor Kirchner, na Argentina, e Lula, no Brasil, tiveram para a ampliação das esferas de atuação da sociedade civil no Mercosul.

O Consenso de Buenos Aires, de 2003, é um dos marcos desse processo. No documento, a superação de problemas sociais que impedem o exercício pleno da cidadania aparece pela primeira fez como responsabilidade dos países (TAJRA, 2019). É notável, também, a presença crescente da necessidade de maior participação social em documentos oficiais do bloco (as já mencionada Decisões 26/2003 e 30/2003 são exemplos disso).

Outro marco encontrado na literatura é o ano 2006: quando se realizou a I Cúpula Social do Mercosul. Para Martins e Silva (2011), é o início da "segunda geração de mecanismos de participação". É notável que, a partir de então, diversos outros órgãos foram criados para materializar a participação social.

Dentre esses organismos, pode-se destacar o Instituto Social do Mercosul (ISM). Criado com o objetivo de ser “[...] uma instância técnica de pesquisa no campo das políticas sociais e implementação das linhas estratégicas aprovadas pela RMADS [Reunião de Ministros e Autoridades de Desenvolvimento Social do Mercosul], com a finalidade de contribuir para a consolidação da dimensão social como um eixo central no processo de integração do Mercosul” (Decisão 37/2008). 
O órgão foi considerado um espaço importante de participação social pelos entrevistados no documento "Construindo o mapa da participação social no Mercosul” (MERCOSUL, 2015).

Outro organismo de grande valia para o tema é a Unidade de Apoio à Participação Social (UPS), cujas atividades foram iniciadas em 2013. Cujas funções que vão desde a elaboração de estudos sobre a dimensão social e o registro das entidades e organizações sociais, ao financiamento dessas entidades (MERCOSUL, 2010).

É necessário mencionar ainda outros órgãos cujos objetivos precípuos não são propriamente a participação social, mas que são abertos a ela. Esses órgãos são temáticos, portanto as OSCs que participam são aquelas ligadas ao respectivo assunto. O quadro 1 abaixo apresenta esses órgãos, bem com as instâncias desses organismos que são abertas à participação.

QUADRO 1 - ÓRGÃOS ABERTOS À PARTICIPAÇÃO POR TEMÁTICA

\begin{tabular}{|c|c|c|c|c|}
\hline Temática & Vínculo & Órgão & Instâncias de participação & Fonte \\
\hline $\begin{array}{l}\text { Agricultura } \\
\text { familiar }\end{array}$ & GMC & $\begin{array}{l}\text { Reunião Especializada de } \\
\text { Agricultura Familiar (REAF) }\end{array}$ & Reuniões & $\begin{array}{l}\text { Ata } n^{\circ} 01 / 04 \text { da } \\
\text { REAF }\end{array}$ \\
\hline \multirow{2}{*}{$\begin{array}{l}\text { Ciência e } \\
\text { tecnologia }\end{array}$} & \multirow[t]{2}{*}{ GMC } & \multirow{2}{*}{$\begin{array}{l}\text { Reunião Especializada de Ciência e } \\
\text { Tecnologia (RECT) }\end{array}$} & $\begin{array}{l}\text { Plataformas, programas, } \\
\text { redes e grupos de trabalho }\end{array}$ & Resolução 24/92 \\
\hline & & & Seções Nacionais & Resolução 24/92 \\
\hline Cooperativas & GMC & $\begin{array}{l}\text { Reunião Especializada de } \\
\text { Cooperativas do Mercosul (RECM) }\end{array}$ & $\begin{array}{l}\text { Reuniões das Seções } \\
\text { Nacionais }\end{array}$ & Resolução 35/01 \\
\hline \multirow[b]{2}{*}{ Cultura } & \multirow[b]{2}{*}{ GMC } & \multirow{2}{*}{$\begin{array}{l}\text { Reunião Especializada de } \\
\text { Autoridades Cinematográficas e } \\
\text { Audiovisuais do Mercosul } \\
\text { (REACA) }\end{array}$} & Consultas esporádicas & Resolução 49/03 \\
\hline & & & $\begin{array}{l}\text { Foro de Competitividade } \\
\text { para o Setor Cinematográfico } \\
\text { e Audiovisual do Mercosul }\end{array}$ & Resolução 49/03 \\
\hline \multirow{2}{*}{$\begin{array}{l}\text { Defesa do } \\
\text { Consumidor }\end{array}$} & \multirow{2}{*}{$\mathrm{CCM}$} & \multirow{2}{*}{$\begin{array}{l}\text { Comitê Técnico de Defesa do } \\
\text { Consumidor (CTDC) }\end{array}$} & Reuniões esporádicas & Diretriz 01/95 \\
\hline & & & Seminários técnicos & Diretriz 01/95 \\
\hline $\begin{array}{l}\text { Dimensão } \\
\text { social }\end{array}$ & $\mathrm{CMC}$ & $\begin{array}{l}\text { Reunião de Ministros e Autoridades } \\
\text { de Desenvolvimento Social } \\
\text { (RMADS) }\end{array}$ & Seminários & Decisão 61/00 \\
\hline $\begin{array}{l}\text { Direitos da } \\
\text { criança e do } \\
\text { adolescente } \\
\end{array}$ & GMC & $\begin{array}{l}\text { Reunião Especializada de Juventude } \\
\text { (REJ) }\end{array}$ & Reuniões esporádicas & Resolução 39/06 \\
\hline \multirow{3}{*}{$\begin{array}{l}\text { Direitos } \\
\text { Humanos }\end{array}$} & $\mathrm{CMC}$ & $\begin{array}{l}\text { Reunião de Autoridades sobre } \\
\text { Povos Indígenas do Mercosul } \\
\text { (RAPIM) }\end{array}$ & Reuniões & Decisão 14/14 \\
\hline & \multirow[b]{2}{*}{$\mathrm{CMC}$} & \multirow{2}{*}{$\begin{array}{l}\text { Reunião de Altas Autoridades de } \\
\text { Direitos Humanos do Mercosul e } \\
\text { Estados Associados (RAADH) }\end{array}$} & Reuniões (terceira sessão) & Decisão 26/03 \\
\hline & & & $\begin{array}{l}\text { Instituto de Políticas Públicas } \\
\text { em Direitos Humanos }\end{array}$ & Decisão 26/03 \\
\hline \multirow[b]{2}{*}{ Educação } & \multirow[b]{2}{*}{$\mathrm{CMC}$} & \multirow{2}{*}{$\begin{array}{l}\text { Reunião de Ministros da Educação } \\
\text { (RME) }\end{array}$} & Foro Educativo Mercosul & Decisão 07/91 \\
\hline & & & $\begin{array}{l}\text { Plataforma de Organizações } \\
\text { Educativas para o Mercosul }\end{array}$ & Decisão 07/91 \\
\hline Gênero & $\mathrm{CMC}$ & $\begin{array}{l}\text { Reunião de Ministras e Altas } \\
\text { Autoridades da Mulher (RMAAM) }\end{array}$ & Reuniões & Resolução 20/98 \\
\hline $\begin{array}{l}\text { Meio } \\
\text { ambiente }\end{array}$ & $\mathrm{CMC}$ & $\begin{array}{l}\text { Reunião de Ministros do Meio } \\
\text { Ambiente (RMMA) }\end{array}$ & Consultas esporádicas & Decisão 19/03 \\
\hline Saúde & $\mathrm{CMC}$ & & Seminários técnicos & Decisão 03/95 \\
\hline
\end{tabular}




\begin{tabular}{cllll} 
& & $\begin{array}{l}\text { Reunião de Ministros da Saúde } \\
\text { (RMS) }\end{array}$ & $\begin{array}{l}\text { Comissão de Saúde e } \\
\text { Desenvolvimento para o } \\
\text { Mercosul, Bolívia e Chile }\end{array}$ & Decisão 03/95 \\
\hline \multirow{2}{*}{ GMC } & $\begin{array}{l}\text { Comissão Socio-laboral do } \\
\text { Mercosul (CSLM) }\end{array}$ & Reuniões & $\begin{array}{l}\text { Resolução 15/99 e } \\
\text { Resolução 12/00 }\end{array}$ \\
\cline { 2 - 5 } Trabalhista & $\begin{array}{l}\text { Grupo de Alto Nível Estratégia } \\
\text { Cercosul de Crescimento do } \\
\text { Emprego (GANEMPLE) }\end{array}$ & Reuniões (etapa deliberativa) & Decisão 46/04 \\
\cline { 2 - 5 } & GMC & $\begin{array}{l}\text { Observatório do Mercado de } \\
\text { Trabalho (OMT) }\end{array}$ & Reuniões & Resolução 45/08 \\
\cline { 2 - 5 } & GMC & $\begin{array}{l}\text { Subgrupo de Trabalho n }{ }^{\circ} 10- \\
\text { Assuntos Laborais, Emprego e } \\
\text { Seguridade Social (SGT-10) }\end{array}$ & Reuniões (etapa preparatória) Resolução 20/95 \\
\hline
\end{tabular}

FONTE: o autor com base no documento "Construindo o mapa da participação social no Mercosul" (MERCOSUL, 2015).

Com base no quadro 1, é possível perceber que, ao longo do desenvolvimento da integração regional, foi aberta uma série de espaços para o diálogo com a sociedade civil. De acordo com Mariano (2015), embora lógica intergovernamental tenha sido mantida na construção institucional, “[...] a nova realidade demanda maior envolvimento das esferas de representação social especialmente dos políticos -, como forma de aumentar a accountability e a democracia no seu interior".

Outro ponto importante a ser destacado é que a participação pode ocorrer de diferntes formas. Seja com a presença em reuniões, seja em seminários. Há, ainda, variações na institucionalidade da participação, ou seja, em alguns casos a presença está baseada em regulamentos do órgão, como é o caso do SGT-10, em outros ela é pontual, como exemplo é possível citar a REJ.

Contudo, a literatura (sistematizada no Quadro 2 a seguir) identificou uma gama de arestas que reduzem os incentivos à participação social. Dentre elas, pode-se mencionar aquelas ligadas a:

1) dificuldades institucionais: (i) a intergovernamentalidade do bloco; (ii) a característica consultiva dos órgãos em que a sociedade civil está presente; e (iii) falta de regras bem definidas para a participação;

2) heterogeneidade dos atores da sociedade civil: (iv) forte grau de elitização da representação dos atores sociais; (v) maior representação de empresários do que de trabalhadores; (vi) falta de recursos financeiros; (vii) alta rotatividade dos representantes; e (viii) problemas para lidar com alta tecnicidade de alguns temas; e

3) atuação das burocracias estatais: (viii) falta de uma visão de processo por parte dos tomadores de decisão; e (ix) cultura de insulamento burocrático. 
O Quadro 2 abaixou buscou sistematizar os trabalhos de acordo com os órgãos ou iniciativas que foram estudados, as dificuldades enfatizadas para a participação da sociedade civil e as dimensões que foram consideradas para analisar o fenômeno.

\begin{tabular}{|c|c|c|c|}
\hline Referência & $\begin{array}{l}\text { Órgãos/iniciativas } \\
\text { analisados }\end{array}$ & $\begin{array}{l}\text { Dificuldades para a } \\
\text { participação }\end{array}$ & Dimensões da participação \\
\hline $\begin{array}{l}\text { (ALEMANY; } \\
\text { LEANDRO, 2006) }\end{array}$ & $\begin{array}{l}\text { FCES; CSLM; Reunião } \\
\text { Especializada da } \\
\text { Mulher (substituído pela } \\
\text { RMMAM); REAF; } \\
\text { RECM; GANEMPLE; } \\
\text { RAADH }\end{array}$ & $\begin{array}{l}\text { Institucionais; } \\
\text { clareza institucional; } \\
\text { transparência; } \\
\text { heterogeneidade dos atores; } \\
\text { atuação das burocracias estatais }\end{array}$ & $\begin{array}{l}\text { (i) Espaços de participação em nível } \\
\text { nacional } \\
\text { (ii) Mecanismos de transparência a } \\
\text { nível de Mercosul } \\
\text { (iii) Espaços formais de participação } \\
\text { no Mercosul e a visão que os atores } \\
\text { possuem }\end{array}$ \\
\hline
\end{tabular}

\begin{tabular}{|c|c|c|c|}
\hline $\begin{array}{l}\text { (VAZQUEZ, } \\
2008)\end{array}$ & FCES & Institucionais & (i) Institucionalidade* \\
\hline $\begin{array}{l}\text { (MARTINS; } \\
\text { ALBUQUERQUE; } \\
\text { GOMENSORO; } \\
\text { 2011) }\end{array}$ & $\begin{array}{l}\text { Somos Mercosul; CSM; } \\
\text { Programa Mercosul } \\
\text { Social e Participativo } \\
\text { (PMSP) }\end{array}$ & Institucionais & $\begin{array}{l}\text { (i) Institucionalidade* } \\
\text { (ii) Representatividade* }\end{array}$ \\
\hline (CULPI, 2012) & FCES, Parlasul & Institucionais & (i) Institucionalidade* \\
\hline $\begin{array}{l}\text { (MERCOSUL, } \\
\text { 2015) }\end{array}$ & $\begin{array}{l}\text { Órgãos apresentados no } \\
\text { Quadro } 1 \text { deste trabalho; } \\
\text { FCES; CSM; Parlasul }\end{array}$ & $\begin{array}{l}\text { Heterogeneidade dos atores; } \\
\text { clareza institucional }\end{array}$ & $\begin{array}{l}\text { (i) Institucionalidade* } \\
\text { (ii) Representatividade* }\end{array}$ \\
\hline
\end{tabular}

\begin{tabular}{|c|c|c|c|}
\hline $\begin{array}{l}\text { (MESQUITA; } \\
\text { BELÉM LOPES, } \\
\text { 2018) }\end{array}$ & $\begin{array}{l}\text { PMSP; Sistema de } \\
\text { Diálogo e Consulta; } \\
\text { Conselho Consultivo da } \\
\text { Sociedade Civil }\end{array}$ & Institucionais & $\begin{array}{l}\text { (i) Institucionalização } \\
\text { (ii) Potencial inclusivo e } \\
\text { democratizante } \\
\text { (iii) Representatividade }\end{array}$ \\
\hline
\end{tabular}

(i) Contexto político da criação do órgão

(TAJRA, 2019) $\quad$ FCES; CSM; Parlasul $\quad \begin{aligned} & \text { Institucionais; clareza } \\ & \text { institucional; transparência }\end{aligned}$
(ii) Institucionalização
(iii) Potencial inclusivo e democratizante (iv) Regras qualificadas no tocante ao processo decisório

(v) Regras em torno à representação (vi) Publicidade

FONTE: o autor (2020).

* as dimensões não foram citadas literalmente nos textos como uma dimensão de análise, foram, portanto, inferidas com base nas conclusões dos trabalhos.

Com base no recém exposto, é possível perceber que as limitações institucionais para a participação são as mais citadas por essa literatura (presente em 100\% dos trabalhos analisados).

Além disso, Alemany e Leandro (2006) e Mercosul (2015) chamam a atenção para o fato das diferentes capacidades entre as OSCs. Ou seja, organizações com mais recursos (tanto financeiros quanto humanos) tendem a ter mais condições de participar. Isso fica mais evidente pelo fato de que 
as reuniões do Mercosul são realizadas em diferentes cidades dos países-membros, assim, há necessidade de recursos financeiros para deslocamento, por exemplo. Inviabiliza-se, dessa maneira, a presença constante de organizações menores. Essa é uma das razões para a importância que a UPS tem para o tema, já que é uma de suas atribuições apoiar financeiramente algumas OSCs.

A atuação dos burocratas estatais, foi objeto de análise (ainda que não específica sobre isso) por Alemany e Leandro (2006). As autoras conseguiram identificar essa dificuldade por meio de realização de entrevistas com representantes de OSCs. Elas ainda desenham cinco cenários para o Mercosul. Um nível mais profundo de participação, correspondente ao cenário do "Mercosul Cidadão", somente seria viável com grandes alterações institucionais, dentre elas a criação de uma supranacionalidade, sem deixar de lado a questão da representatividade dos atores sociais. Ou seja, a institucionalidade deveria promover a igualdade de oportunidade de acesso à participação.

Se, por um lado, há a crescente retórica participacionista, por outro há limites institucionais fortes. Esse paradoxo, é denominado por Tajra (2019) como o "persistente trade-off da integração sul-americana". Existe um hiato entre as declarações dos presidentes e as decisões, resoluções e diretrizes dos órgãos decisórios do Mercosul e a "condução efetiva e administração cotidiana do bloco" (Caetano, 2019, p.62). Nesse diapasão, Culpi (2012) identificou pouca inclusão dos interesses da sociedade civil nas discussões dentro do Parlasul, e o aprofundamento da participação dos atores sociais que poderia vir do FCES, âmbito de participação por excelência, é inviabilizado por sua falta de legitimidade perante o bloco, persisitndo o "déficit demorcrático".

Outro ponto importante para ser salientado, tendo em vista a condução deste trabalho, é que os estudos identificados no Quadro 2 possuíam um recorte definido por órgãos, podendo ser classificados como estudos de caso. Com exceção do "Construindo o mapa da participação social no Mercosul” (MERCOSUL, 2015), que buscou descrever de maneira mais geral a participação. Portanto, acredita-se que quantificar a participação nos órgãos do Mercosul seja uma contribuição interessante, a fim de identificar os efeitos de todas as dificuldades já analisadas pela literatura na participação social.

\section{MENSURANDO A PARTICIPAÇÃO}

Antes de detalhar melhor o indicador, é importante definir o que se considerou como "participação". De maneira geral, entendeu-se como sinônimo de "presença", isto é, o fato de algum representante da sociedade civil estar presente na reunião. Além disso, a "consulta" a setores da sociedade civil também foi compreendida como participação, por exemplo com a execução de 
seminários nos quais ela participe, ou quando algum especialista em determinada temática é convidado para traz contribuições para a tomada de decisão.

Esse esclarecimento é necessário uma vez que impõe limites às interpretações que se possa fazer do indicador. Alemany e Leandro (2006), por exemplo, enfatizam a necessidade de se entender "participação" em um sentido mais integral, que abarque um sistema de monitoramento, de tomada de decisões que influencie as decisões do bloco. Ou seja, uma ação, para ser classificada como participação, deve influenciar a tomada de decisão, demandando, assim, que se verifique seus resultados. Dadas as limitações do método utilizado aqui, essa ideia de "participação", ainda que mais profunda, não foi possível de ser utilizada satisfatoriamete. O objetivo do indicador, portanto, é mensurar a participação entendida de uma maneira mais superficial, ou seja, como presença ou consulta.

No que diz respeito aos materiais utilizados, foram consultados as atas, as listas de presenças e os anexos (quando necessários) disponíveis digitalmente no site do Mercosul. Os órgãos incluídos na mensuração foram aqueles cujas reuniões estavam registradas no Arquivo Oficial do Mercosul.

Dito isso, passemos para a discussão sobre o indicador. Ele foi formado por três dimensões: (i) institucionalização, (ii) potencial inclusivo e democratizante, e (iii) representatividade. Elas foram baseadas nos trabalhos de Mesquita e Belém Lopes (2018) e Tajra (2019), cujos fundamentos podem ser encontrados no estudo de Faria e Ribeiro (2011), sobre indicadores relevantes para processos participativos.

A dimensão institucionalização buscou refletir a participação propriamente dita, a existência de regras para a participação (pelo menos a estabilidade de sua ocorrência), e a função dos órgãos nos quais a sociedade civil participou.

A segunda dimensão, potencial inclusivo e democratizante, segundo Faria e Ribeiro (2011), pode incluir regras sobre composição, pluralidade e proporcionalidade dos participantes e regras do processo decisório, "no qual são analisadas as normas referentes a distribuição, concentração e alternância de poderes em relação a formulação das normas de funcionamento, definição da pauta e tomada de decisão" (Faria \& Ribeiro, 2011, p. 128). Para esta pesquisa, entendeu-se que as regras sobre pluralidade de atores da sociedade civil estão vinculadas ao apoio estatal e do bloco. Isto é, a existência de órgãos nacionais que busquem incentivar a participação de diferentes atores sociais, bem como a existência de órgão no âmbito mercosulino dedicado a realizar esse apoio (no caso, a UPS). Dessa forma, o potencial inclusivo e democratizante é avaliado no Mercosul como um todo, e não órgão por órgão. Nada impede, todavia, que um estudo futuro possa olhar essas regras caso a 
caso a fim de utilizar a dimensão de maneira mais próxima com aquilo pensado por Faria e Ribeiro (2011), e aplicado por Mesquita (2018) e Tajra (2019).

A dimensão representatividade foi baseada em Mesquita e Belém Lopes (2018). Ela é semelhante ao potencial inclusivo e democratizante, contudo, enquanto esta olha para as regras, aquela preocupa-se em medir a participação de diferentes atores da sociedade civil. Isto é, o quão plural foi a participação. O Quadro 3 abaixo sistematiza o que foi mencionado e apresenta as variá'veis utilizadas para cada dimensão.

QUADRO 3 - DIMENSÕES, PROXIES, CÁLCULOS E PESOS DAS VARIÁVEIS DO INDICADOR.

\begin{tabular}{|c|c|c|c|}
\hline Dimensão & Variável & Cálculo & Peso \\
\hline \multirow{3}{*}{ Institucionalização } & X1: média do nível dos órgãos aberto à participação & $\frac{\sum P_{j} \cdot h_{j}}{p}$ & 1 \\
\hline & X2: órgãos com a presença institucionalizada & $\frac{i}{n}$ & 1 \\
\hline & $\begin{array}{l}\text { X3: órgãos cujas reuniões contaram com a } \\
\text { participação de atores da sociedade civil }\end{array}$ & $\frac{p+c}{n}$ & 1 \\
\hline \multirow{2}{*}{ Potencial inclusivo e democratizante } & $\begin{array}{l}\text { X4: existência de órgão responsável para organizar } \\
\text { a participação }\end{array}$ & $\begin{array}{l}0=\text { não existe } \\
1=\text { existe }\end{array}$ & 0,33 \\
\hline & $\begin{array}{l}\text { X5: órgãos ou iniciativas nacionais para apoiar a } \\
\text { participação }\end{array}$ & $\frac{o}{e}$ & 1 \\
\hline \multirow[b]{2}{*}{ Representatividade } & $\begin{array}{l}\text { X6: áreas com órgãos abertos à participação da } \\
\text { sociedade civil }\end{array}$ & $\frac{a^{\prime}}{a}$ & 1 \\
\hline & $\begin{array}{l}\text { X7: existência de eventos/iniciativas com o } \\
\text { objetivo de representar amplamente a sociedade } \\
\text { civil }\end{array}$ & $\begin{array}{l}0=\text { não existe } \\
1=\text { existe }\end{array}$ & 0,33 \\
\hline
\end{tabular}

Onde:

$P_{j}=$ (houve participação no órgão $j \rightarrow 1$; não ouve participação no órgão $j \rightarrow 0$ );

$h_{j}=$ ( $j$ é órgão decisório ou não está subordinado a um órgão decisório $\rightarrow 1$; $j$ é órgão diretamente subordinado a um órgão decisório $\rightarrow 0,75 ; j$ é órgão subordinado a um de nível $0,75 \rightarrow 0,50 ; j$ é órgão subordinado a um de nível $0,50 \rightarrow 0,25 ; j$ é órgão subordinado a um de nível $0,25 \rightarrow 0,00$ );

$p=$ número de órgãos que contaram com a presença da sociedade civil;

$i=$ número de órgãos que contaram com a participação da sociedade civil em pelo menos $80 \%$ de suas reuniões;

$n=$ número total de órgãos que realizaram pelo menos uma reunião no ano em questão;

$c=$ número de órgãos que realizaram consultas à sociedade civil;

$o=$ número de órgãos/iniciativas nacionais para apoiar a participação;

$e=$ número de Estados-membro não suspensos;

$a^{\prime}=$ número de áreas da integração que pelo menos um de seus órgãos contou com a participação da sociedade civil no ano em questão;

$a=$ número total de áreas da integração cujos órgãos realizaram pelo menos uma reunião no ano em questão.

FONTE: o autor (2020). 
Os cálculos foram realizados ano a ano, a fim de enxergar as transformações ao longo do tempo. As variáveis situam-se em um intervalo de 0 a 1 , por isso, para reduzir as distorções causadas pelas variáveis dicotômicas (X4 e X7), optou-se por atribuí-lhes um peso de 0,33.

Mais um esclarecimento se faz necessário com relação à variável X2, presença institucionalizada. Esse tipo de presença foi considerada para os órgãos cuja presença da sociedade civil foi identificada em mais de $80 \%$ de suas reuniões. Exemplificando: se determinado órgão, durante todo o período analisado, contou com a presença de atores da sociedade civil em pelo menos $80 \%$ de suas reuniões, considera-se que a tenha institucionalizado. Assim, se houve reunião desse mesmo órgão no ano analisado, ele é contabilizado como 1. A somatória de todos esses casos resulta na variável $i$.

Com relação ao fenômeno da consulta, entende-se que também é um tipo de participação, já que tratar da participação social somente da "perspectiva dos espaços institucionais habilitados para esses fins pode fazer perder de vista o fato de que existem níveis importantes de interrelação e formas indiretas de participação social não canalizadas através desses mecanismos” (Mercosul, 2015, p.11).

Além disso, a participação considerada é aquela envolvida no processo de tomada de decisão. Ou seja, aquela que contribuiu, de alguma forma, para os debates das reuniões. Portanto projetos sociais do Mercosul (como o Somos Mercosul e o Sistema Integrado de Mobilidade) não foram contabilizados como consulta, justamente porque o indicador teve o intuito de medir a presença na tomada de decisão. Um projeto social é em si uma decisão. Com a ressalva de que, caso tenha sido verificado, nas atas, que houve contribuições desses projetos para as discussões das reuniões, contabiliza-se como consulta (por exemplo o caso do Parlamento Juvenil e das Consultas Públicas realizadas pelo Instituto de Políticas Públicas em Direitos Humanos).

As agregações das variáveis foram realizadas por meio de médias ponderadas de cada dimensão. Dessa forma, o Indicador de Participação Social, é composto pela somatória das três médias. Variando, portanto, de 0 a 3. Com isso é possível estabelecer uma escala qualitativa da participação social: entre 0 e 0,6: muito baixa; acima de 0,6 até 1,2: baixa; acima de 1,2 até 1,8: média; acima de 1,8 até 2,4: alta; e acima de 2,4: muito alta participação social.

\section{O INDICADOR DE PARTICIPAÇÃO SOCIAL (IPS)}

A coleta de dados ainda não foi completamente terminada, como fica demonstrado no Gráfico 1. Priorizou-se, então, as reuniões dos últimos cinco anos do bloco. Das demais reuniões, foram coletados os dados prioritariamente dos órgãos que possuíram a participação institucionalizada (do 
SGT-10, por exemplo) e daqueles subordinados ao CMC. O total de reuniões cujos dados foram analisados foi 2.832, representando cerca de 35\% das reuniões registradas. O gráfico a seguir demonstra o status da coleta com base na quantidade de órgãos, ou seja, os percentuais foram calculados tendo como denominador o número de órgãos que detinham pelo menos uma reunião registrada no ano em questão.

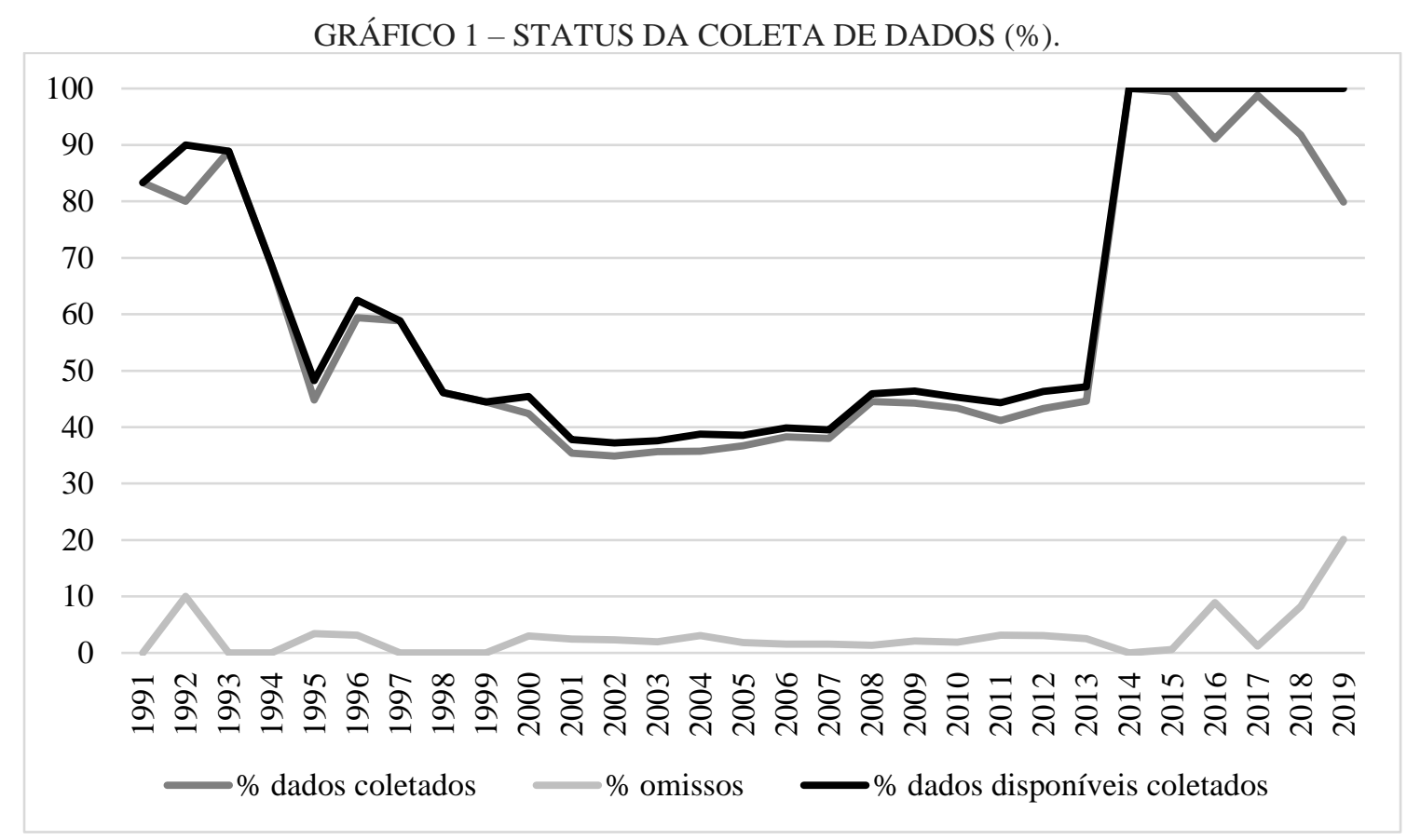

FONTE: o autor (2020).

Duas aclarações são necessárias por conta do status da coleta: (i) os cálculos foram realizados em uma perspectiva relativa, ou seja, tendo por base apenas as informações coletadas; e (ii) os casos omissos, crescentes a partir de 2018, foram desconsiderados, todavia, como os cálculos foram em termos relativos, reduz-se o viés, ainda que não o elimine completamente.

No que diz respeito à variável $\mathrm{X} 4$, existência de órgão responsável para organizar a participação, a criação da UPS foi o marco fundamental. A partir de 2010, a variável assume valor um, já que esse órgão tem como objetivo fornecer apoio, inclusive financeiro, para a participação social. Trata-se, entretanto, de potencial, não da atuação prática. A obtenção de novos dados, por exemplo, o quanto a UPS conseguiu financiar OSCs, poderia trazer um indicador mais próximo da realidade.

A variável X5, órgãos ou iniciativas nacionais para apoiar a participação, buscou captar a importância do apoio dos Estados para a participação. As iniciativas encontradas foram: na Argentina, o Consejo Consultivo de la Sociedade Civil (CCSC), criado em 2003, porém com a primeira reunião 
em 2005, permanecendo em atividade até 2019; no Brasil, o Programa Mercosul Social e Participativo (PMSP), criado em 2005 com a última reunião encontrada em 2015; e no Uruguai, o Sistema de Diálogo y Consulta (SDC), criado em 2015 e o último encontro registrado foi em $2018^{3}$.

Sobre a variável X6, áreas com órgãos abertos à participação da sociedade civil, foram identificadas 22 áreas de integração, são elas: Administrativo, Agricultura, Ciência e Inovação, Comércio, Comunicação, Cooperação Jurídica, Cultura, Democracia, Direitos Humanos, Economia, Educação, Energia, Gênero, Indústria, Integração, Meio Ambiente, Política, Saúde, Segurança, Social, Trabalhista e Turismo.

Com relação à variável X7, existência de eventos/iniciativas com o objetivo de representar amplamente a sociedade civil, foram considerados como casos positivos aqueles anos em que ocorreram as Cúpulas Sociais do Mercosul, tendo em vista a importância e o tamanho que esses encontros possuíam (LAISNER; CAMARGO, 2013; SILVA; MARTINS, 2015). Elas foram organizadas pela primeira vez em 2006, seguindo ininterruptamente até 2016. A partir de então não foram mais realizadas até 2019. Dito isso, o Gráfico 2 apresenta os resultados do IPS.

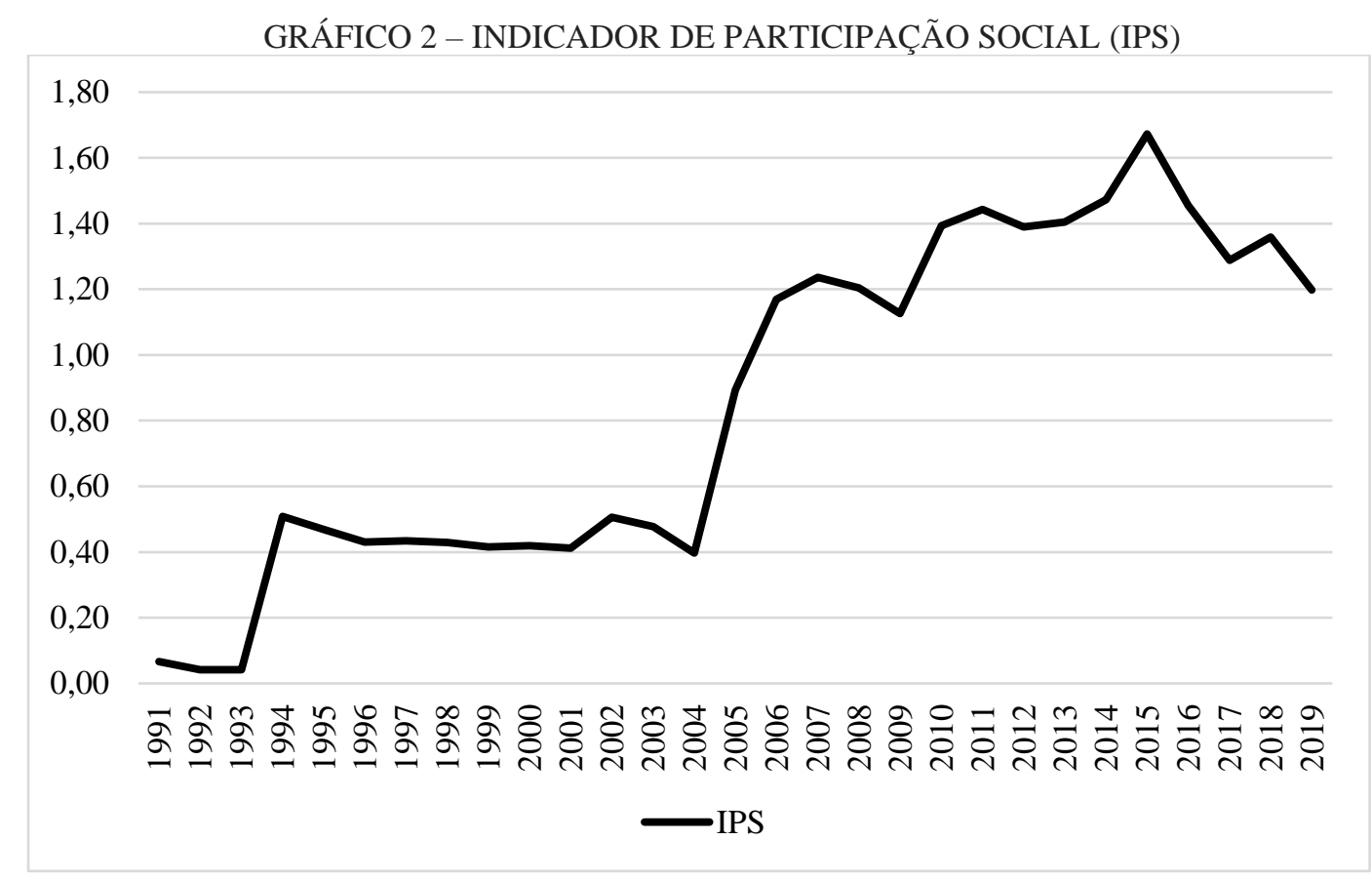

FONTE: o autor (2020).

\footnotetext{
${ }^{3}$ As informações referentes até o ano de 2016 foram baseadas na tese de doutoramento de (MESQUITA, 2016). Para os demais anos, foi realizado uma pesquisa nos sites oficiais: para o caso argentino, ver https://www.argentina.gob.ar/sinagir/institucional/ong/consejo-consultivo-sociedad-civil/minutas; para o uruguaio, https://sdc.mrree.gub.uy/. Para o Programa Mercosul Social e Participativo não foram encontradas informações disponíveis online. Portanto, considerou-se o último ano reportado por Mesquita (2016).
} 
O Gráfico 2 permite-nos identificar três fases da participação social e o início de uma possível quarta fase. A primeira, de 1991 a 1993, a ser chamada de "fase do ensaio" de participação muito baixa; a segunda, entre 1994 e 2004, denominada como "fase do prólogo", também de participação muito baixa; a terceira, de 2005 a 2015, "fase do desenvolvimento", de participação baixa chegando a média; e a possível quarta fase, a partir de 2016, chamada de "fase da incógnita", de redução para baixa participação novamente.

A fase do ensaio tem por característica uma atuação pontual e experimental de poucos atores da sociedade civil. Como é o caso da Coordenadora das Centrais Sindicais do Cone Sul, que apresentou à Reunião de Ministros do Trabalho, já em 1991, suas propostas para a integração, as quais obtiveram resultados concretos, com a criação do SGT-11, para citar um exemplo (BAPTISTA, 2020; BARBIERO; CHALOULT, 2007; MARIANO, 2011; ORTEGA, 2010). Além disso, é um período de preparo do Mercosul, onde suas instituições ainda estavam sendo gestadas, cujo resultado é o Protocolo de Ouro Preto, inaugurando a segunda fase.

A partir de 1994 até 2004, a fase do prólogo, portanto, é marcada por um crescimento da participação social, seguida de uma estabilização. É a estreia de uma maior institucionalização do Mercosul. A criação de vários organismos, notadamente o FCES, pode ser entendida como a causa desse aumento. Todavia, não é observado um crescimento nos anos seguintes, o foco comercialista do bloco, a ideia do "Mercosul Mínimo" (MARIANO, 2015), do regionalismo aberto, em suma, do foco comercialista podem ser colocados como obstáculos para o aumento da participação social. O que é, de certa forma, superado a partir de 2003, com os governos de Néstor Kirchner e Lula, cujos resultados podem ser verificados concretamente a partir de 2005, marco da terceira fase.

A fase do desenvolvimento, entre 2005 e 2015, é caracterizada pelo crescimento da participação social, notadamente por conta da criação de órgãos e iniciativas nacionais de apoio. É nesse contexto que são criados o CCSC, o PMSP e o SDC. É, também, quando o regionalismo aberto dá lugar ao pós-liberal ou pós-hegemônico. É o período de relançamento do Mercosul, com o aprofundamento de várias dimensões da integração, entre elas a social, que inclui a participação da sociedade civil. Em suma, é possível ver esses movimentos refletidos pelo IPS.

O ano de 2016 pode ser o marco do início de uma quarta fase, por isso foi chamada de "fase da incógnita". A crise econômica acompanhada de crise política no Brasil, com o impeachment de Dilma Rousseff; e a ascensão de governos que possuem o ideal de Mercosul como liberalcomercialista (CAETANO, 2019), notadamente Macri e Bolsonaro, podem indicar uma possível reversão de tendência no que tange à participação da sociedade civil, uma vez que a dimensão social 
perde ênfase. Para detalhar melhor a evolução do IPS, apresenta-se o Gráfico 3, com o indicador desagregado por dimensão.

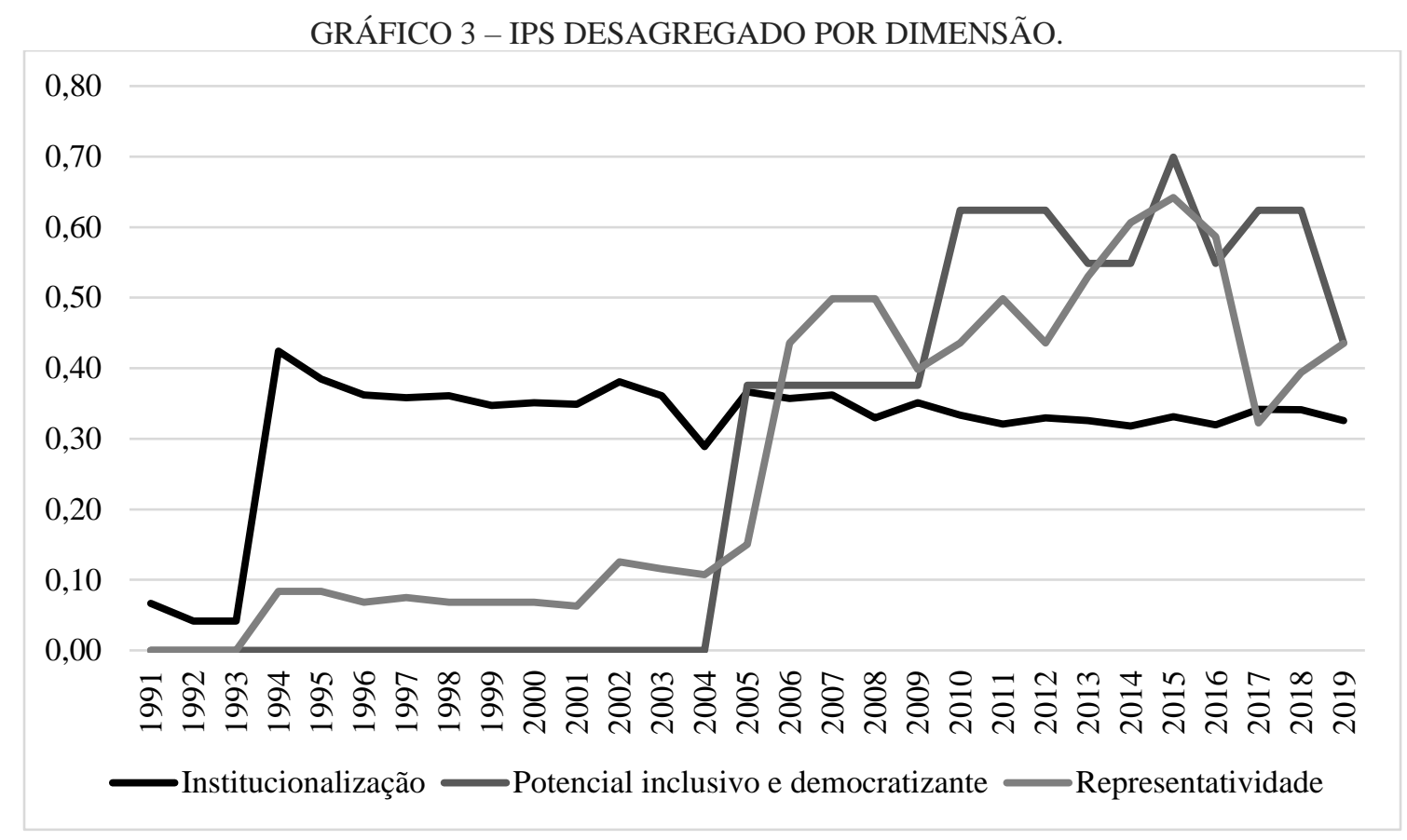

FONTE: o autor (2020).

Antes de detalhar cada dimensão, optou-se por classificá-las em uma escala de 0 a1, onde: entre 0 e 0,2 é muito baixo; acima de 0,2 até 0,4, baixo; acima de 0,4 até 0,6, médio; acima de 0,6 até 0,8 , alto; e acima de 0,8 , muito alto.

A análise da dimensão Institucionalização permite identificar uma tendência levemente negativa ao longo dos anos, mantendo-se grande parte do tempo em um nível baixo. Isso ocorreu em virtude da redução da variável X1, que caiu 39\% entre 1994 e 2019. Apesar de o número relativo de órgãos abertos à participação (institucionalizada ou não), isto é, X2 e X3, ter aumentado aproximadamente $54 \%$ e $27 \%$ respectivamente no mesmo período. Conclui-se que a participação foi, ao longo do tempo, sendo mais frequente nos órgãos de terceiro nível, comissões e subcomissões de órgãos consultivos.

O Potencial Inclusivo e Democratizante refletiu as dinâmicas nacionais de apoio à participação. Passando por um período longo quando não havia essas iniciativas nacionais. As efetivações do CCSC e do PMSP inauguram a "fase do desenvolvimento" da participação social, cujas motivações podem ser encontradas internamente em cada Estado-membro. O ano de 2010 também é relevante porque é o ano de criação da UPS, cuja quantificação foi captada pela variável X4, elevando a dimensão para um nível alto. 2015 é o ápice, pois é quando três dos quatro Estados- 
membro ativaram aquelas iniciativas de apoio. Contudo, no ano de 2016, não foram mais identificadas reuniões do PMSP. Em 2019, também não foram encontradas reuniões do CCSC, caindo para um nível médio de Potencial Inclusivo e Democratizante. O que fortalece a hipótese de uma quarta fase.

A dimensão da Representatividade manteve uma tendência crescente a partir de 2001, que se acelera em 2006, encerrando-se em 2016. Embora tenha ocorrido essa queda, notadamente em virtude da não realização das CSMs, houve um aumento considerável, de aproximadamente 420\% entre 1994 e 2019, na variável X6. Ou seja, a participação que era basicamente limitada à área Trabalhista em 1994, passou a incluir diversas outras temáticas, como: Agricultura, Ciência e Inovação, Democracia, Direitos Humanos, Educação, Gênero, Integração, Saúde e Turismo. Isso demonstra uma ampliação das entidades da sociedade civil capazes de participarem e um diálogo mais amplo com a sociedade por parte do bloco. Contudo, passa de um nível alto, em 2015, para médio em 2019.

\section{CONCLUSÕES E DISCUSSÕES}

Iniciamos este texto mencionando os desafios impostos ao Mercosul decorrentes das divergências entre Argentina e Brasil. Após apresentar um brevíssimo histórico da integração, verificou-se o papel importante dos governos nacionais para a questão da participação, bem como a série de entraves que ainda persistem para o seu fortalecimento.

A partir do indicador, foi possível distinguir três fases da participação social e o possível início de uma quarta. Essa divisão foi coerente com outras já estabelecidas pela literatura. Como a realizada por Onuki (2006), que, até o ano da publicação do livro em questão, tinha identificado três fases: de 1991 a 1994, de constituição do bloco; de 1994 a 1999, de crescente interdependência e disputas comerciais; e de 1999 a 2006, de crises domésticas e refundação do bloco.

Sobre outras bases, Almeida (2016) identifica um período de “crise e recuo geral” entre 1999 e 2002, para em seguida passar para uma fase de "fins políticos" (2003-2016), dada a aproximação e convergências ideológicas entre os quatro presidentes à frente dos Estados-membros.

As quatro fases identificadas por este trabalho vão ao encontro das duas mencionadas anteriormente. A primeira, a fase do ensaio, corresponde a esse período de fundação e de constituição do bloco, o qual também é um período de primeiras aproximações pontuais entre Mercosul e sociedade civil. A segunda, a fase do prólogo, é concomitante às fases de crescente interdependência e institucionalização do bloco advinda do Protocolo de Ouro Preto. Aqui há uma diferença, já que Onuki (2006) e Almeida (2016) enfatizam bastante as disputas comerciais entre os países. Essas celeumas não parecem ter causado grandes mudanças no que tange à participação. 
A terceira fase, a do desenvolvimento, coaduna-se com a ideia de que a aproximação entre os presidentes tenha fortalecido a dimensão social. Percebe-se que nesse período ganha importância a perspectiva nacional, ou seja, os órgãos e iniciativas nacionais para apoiaram a participação social no Mercosul.

A hipótese da fase da incógnita, não identificada pelos trabalhos mencionados por conta das limitações temporais, pode ser fortalecida pelo trabalho de Caetano (2019), o qual discorre sobre possíveis impactos dos perfis mais "liberal-comercialistas" dos presidentes Mauricio Macri e Michel Temer. O autor argumenta a favor da hipótese do "giro refundacional" do Mercosul. Com base nisso, é possível entender a queda no IPS nos anos recentes como consequência dessas mudanças políticas nos países.

Dado o nível baixo da dimensão institucionalização, entende-se que a atuação dos Estados é fundamental para os rumos da participação social. Assim, o quanto a sociedade civil possa influenciar a formulação de agenda do bloco dependerá da vontade estatal de ouvi-los. Divergências entre algum dos governos e atores da sociedade civil no âmbito do bloco não parecem oferecer sérios riscos de inviabilizar a atuação do Mercosul.

Concordamos com Caetano (2019) quando ele afirma que os problemas de institucionalização são um processo histórico. Ao mencionar diversos objetivos não alcançados do Mercosul (para citar alguns: a questão da assimetria entre os membros, falta de concertação em foros multilaterais, poucos avanços em matéria de agenda externa comum, entre outros), o autor remete a uma entrevista a José Mujica em que o ex-presidente fala da "mentira institucional" (EL OBSERVADOR, 2014), ou seja, as divergências entre o que está escrito e o que está sendo feito. No que diz respeito à participação social, é um problema que está presente desde o início, como é possível verificar pela dimensão institucionalização do IPS. Indo ao encontro da literatura sobre participação social no Mercosul, das quais todos os trabalhos ressaltam os problemas oriundos da baixa institucionalização (ALEMANY; LEANDRO, 2006; CULPI, 2012; MARTINS; ALBUQUERQUE; GOMENSORO, 2011; MERCOSUL, 2015; MESQUITA; BELÉM LOPES, 2018; TAJRA, 2019; VAZQUEZ, 2008).

Mencionamos na introdução deste trabalho a hipótese de Malamud (2011) de que não se deveria esperar que maior abertura gerasse mais participação. O que podemos afirmar, ainda que não descartar completamente essa hipótese, é que existe uma “participação apesar de” todos os problemas. As variáveis X2 e X3, que buscaram mensurar a participação em reuniões do Mercosul (institucionalmente no segundo caso), aumentaram 54 e 27\% entre 1994 e 2019. Isso demonstra uma participação que cresceu em termos relativos apesar de todos os seus limites. 
Além disso, é valido realizar alguns comentários sobre os limites do indicador. Um primeiro que poderia ser mencionado é que ele não capta precisamente a dimensão nacional, ou seja, a participação nas sessões nacionais. Outro limite necessário é que o IPS não procurou quantificar o perfil das OSCs participantes. Isso pode ser particularmente problemático tendo em vista que a questão da heterogeneidade dos atores é um dos pontos elencados como dificuldades para a participação (ALEMANY; LEANDRO, 2006).

O perfil das OSCs é um assunto que pode render futuros trabalhos, uma vez que, durante a coleta de dados, foi possível identificar mudanças significativas nos perfis das entidades que participaram nas reuniões, notadamente em 2019. O que pode remeter à questão da autonomia dos atores da sociedade civil que estão presentes nos espaços mercosulinos.

O IPS preocupou-se em olhar para dentro do Mercosul. Porém, o que acontece fora do bloco, nas sociedades, é algo que deve ser levado em conta para falar de legitimidade do bloco. Como é frequente encontrar a associação "mais participação, mais legitimidade", acredita-se que olhar somente para o processo intramercosul não seja suficiente para realizar essa conexão. Há a dimensão da identidade e da opinião pública que não foi trazida para este trabalho.

O Mercosul, com quase 30 anos de existência, passa pelo que pode ser o seu maior teste, já que é a primeira vez que os governos dos seus dois principais sócios possuem visões de mundo amplamente divergentes. Em tal cenário, pode ser ainda mais relevante o papel dos atores sociais para a continuidade da integração regional. Há o desafio adicional de que a participação social não logrou maior institucionalização, ficando, em larga medida, dependente dos governos nacionais. 


\section{REFERÊNCIAS}

ALEMANY, C.; LEANDRO, B. Análisis y propuestas para la participación ciudadana en el MERCOSUR. Análisis y propuestas, 2006.

ALMEIDA, P. R. DE. O MERCOSUL aos 25 anos: minibiografia não autorizada. Mundorama, 2016.

BAPTISTA, J. V. DA M. A Central Única dos Trabalhadores (CUT) e o Mercosul: conflitos e contradições da participação social nos governos Lula da Silva e Dilma Rousseff (2003-2014). Pograma Santiago Dantas, 2020.

BARBIERO, A.; CHALOULT, Y. Desafios, estratégias e alianças das centrais sindicais no Mercosul. Civitas - Revista de Ciências Sociais, v. 1, n. 1, p. 55, 2007.

CAEtAnO, G. Mercosul: quo vadis? Diplomacia, Estratégia e Política, v. 5, p. 144-181, 2007.

CAETANO, G. Breve historia del MERCOSUR en sus 20 años. Coyunturas e instituciones (19912011). In: CAETANO, G. (Ed.). Mercosur: 20 años. CEFIR, 2011. p. 21-74.

CAETANO, G. Los nuevos rumbos del Mercosur. El cambio de modelo y las consecuencias de la crisis brasileña. Foro Internacional, v. 235, n. 1, p. 47-88, 2019.

CLARÍN. Los gobiernos reafirman el Mercosur pero crecen las dudas. 9 maio 2000.

CULPI, L. A. A participação da sociedade civil nas instituições comunitárias do Mercosul (19912010). Revista Eletrônica de Ciência Política, v. 3, p. 31-48, 2012.

DANESE, S. Diplomacia presidencial. História e crítica. Rio de Janeiro: TopBooks, 1999.

DRI, C. F.; PAIVA, M. E. Parlasul, um novo ator no processo decisório do Mercosul? Revista de Sociologia e Política, v. 24, n. 57, p. 31-48, 2016.

EL OBSERVADOR, E. Arremete Mujica contra países del MERCOSUR. El Observador, 11 jan. 2014.

FARIA, C. F.; RIBEIRO, U. C. Desenho institucional: Variáveis relevantes e seus efeitos sobre o processo participativo. In: PIRES, R. R. C. (org.) Efetividade das instituições participativas no Brasil: estratégias de avaliação. Brasília: Ipea (Diálogos para o desenvolvimento), 2011. p. 125135 .

LAISNER, R. C.; CAMARGO, A. G. O papel das Cúpulas Sociais do Mercosul na (re)definição da democracia em tempos de globalização. Encontro Nacional da Associação Brasileira de Relações Internacionais - ABRI. Anais, 2013.

MALAMUD, A. Conceptos, teorías y debates sobre la integración regional. Norteamérica, v. 6, n. 2, p. 219-249, 2011.

MARIANO, K. L. P. Participação das centrais sindicais no Mercosul (1991-2010). São Paulo: Cultura Acadêmcia, 2011. 
MARIANO, K. L. P. Regionalismo na América do Sul: um novo esquema de análise e a experiência do Mercosul. São Paulo: Editora UNESP; Cultura Acadêmica, 2015.

MARTINS, J.; ALBUQUERQUE, C.; GOMENSORO, F. MERCOSUL social e participativo: a ampliação da esfera pública regiona In: CAETANO, G. (Ed.). Mercosur: 20 años. Montevidéu, CEFIR, 2011.

MARTINS, J. R. V.; SILVA, C. A. Políticas sociais e participação social: a constituição de uma esfera pública regional no mercosul. Boletim de Economia e Política Internacional, v. 5, 2011.

MERCOSUL. Decisão 37/2008 - Estrutura do Instituo Social do Mercosul, 2008.

. Decisão 65/2010 - Unidade Apoio à Participação Social, 2010.

Construindo o mapa da participação social no Mercosul. Montevidéu: Unidade de Apoio à Participação Social, 2015.

MESQUITA, L. R. Representação, democracia e política externa: a participação social como indutora de mudanças na política externa? p. 224, 2016.

MESQUITA, L. R.; BELÉM LOPES, D. Does participation generate democratization? Analysis of social participation by institutional means in Argentine, Brazilian and Uruguayan foreign policies. Journal of Civil Society, v. 14, n. 3, p. 222-240, 2018.

ONUKI, J. O Brasil e a construção do Mercosul. In: OLIVEIRA, H. A. DE; LESSA, A. C. (Eds.). . Relações internacionais do Brasil: temas e agendas, v.1. São Paulo: Saraiva, 2006.

ORTEGA, V. M. O sindicalismo no mercosul: As propostas das centrais sindicais. UFSC, 2010.

RIBEIRO, E. DE S. MERCOSUL: sobre democracia e instituições. Brasília: UniCEUB, 2018.

RIGGIROZZI, P.; TUSSIE, D. The rise of post-hegemonic regionalism: the case of Latin America. Springer, Dordrecht, 2012.

SANAHUJA, J. A. Regionalismo multilateralismo post-liberal y El caso de UNASUR en Sudamérica: In: El regionalismo "post-liberal" en América Latina y el Caribe: Nuevos actores, nuevos temas, nuevos desafíos. 2012.

SERBIN, A.; MARTINEZ, L.; RAMANZINI JÚNIOR, H. El regionalismo "post-liberal” en América Latina y el Caribe: Nuevos actores, nuevos temas, nuevos desafíos. 2012.

SILVA, C. A.; MARTINS, J. R. V. As Cúpulas Sociais do MERCOSUL I. 2015.

TAJRA, J. L. F. Abertura institucional e democratização da integração sul-americana: possibilidades e limites da participação social no MERCOSUL (1991-2018). Universidade Federal do Rio Grande do Sul, 2019.

VAZQUEZ, M. Los escenarios de participación social en el MERCOSUR. Densidades. Revista de Integración Regional Suramericana, v. 1, p. 88-96, 2008. 